\title{
Radiologia digital: como fica o laudo radiológico?
}

\author{
Digital radiology: what about the radiological reports?
}

\author{
Alair Augusto Sarmet M. D. dos Santos*
}

Os avanços na Radiologia parecem não acabar nunca. Estes avanços ocorrem não só no desenvolvimento de novos equipamentos, técnicas e sequências, mas também no suporte tecnológico que auxilia os serviços. Um dos grandes avanços foi o desenvolvimento do Picture Archiving and Communication System (PACS) - sistema de comunicação e arquivamento de imagens -, o que permitiu não só uma melhoria no sistema de arquivamento de imagens e laudos, como também otimizou o fluxo de trabalho nos serviços de Radiologia.

Neste fluxo de trabalho, etapa importante está na elaboração dos laudos radiológicos, que pode ser feita pelo método convencional (no qual o radiologista analisa e interpreta as imagens, elabora um laudo manuscrito, envia para a digitadora, que posteriormente o devolve para a revisão e assinatura do relatório final) ou por laudo ditado (que pode ser feito por meio de fitas cassetes, diversos sistemas de gravação e por ferramentas que podem ser utilizadas no PACS, inclusive reconhecimento de voz e laudo ditado diretamente no computador).

Há muito tempo, com o crescimento dos serviços de Radiologia e Diagnóstico por Imagem, existe a preocupação de se otimizar o fluxo de trabalho. Já em 1997, Seltzer et al. ${ }^{(1)}$, do Departamento de Radiologia da Harvard Medical School, descreveram que entre as diversas medidas para melhorar a qualidade de um serviço de Radiologia estava o uso do laudo ditado e com reconhecimento de voz.

Desde esta época ${ }^{(2)}$ já existiam programas de reconhecimento de voz, nos quais se falava o texto, o computador "ouvia" e digitava diretamente na tela. O sistema usava um vocabulário ou coleção de palavras pré-selecionadas e comparava os sons com este vocabulário, sendo

\footnotetext{
* Doutor, Professor Adjunto e Chefe do Serviço de Radiologia do Hospital Universitário Antônio Pedro - Universidade Federal Fluminense (HUAP-UFF), Niterói, RJ, Brasil, Membro das Comissões de Ensino e Telerradiologia do Colégio Brasileiro de Radiologia e Diagnóstico por Imagem (CBR). E-mail: alairsarmet@globo.com
}

possível o uso de dois tipos de reconhecimento de voz: um em tempo real, no qual o ditado aparecia na estação de trabalho em frente ao radiologista que estava ditando o relatório, ou então se usava o recurso de laudo ditado, que era encaminhado a um outro computador, onde uma outra pessoa (a digitadora) ouvia o laudo e digitava.

Wheeler e Cassimus ${ }^{(3)}$, em 1999, referiram que o uso do PACS e do reconhecimento de voz tiveram um impacto significativo no fluxo de trabalho no complexo hospitalar da Universidade de Emory, Atlanta, EUA (composto de três hospitais separados), relatando que $65 \%$ dos laudos eram feitos em 15 minutos, $80 \%$ em menos de 30 minutos e $90 \%$ em menos de uma hora, com a implementação destas ferramentas. Outros trabalhos confirmaram, posteriormente, a melhoria no fluxo de trabalho com o PACS e o laudo ditado(4-6).

Já existem, hoje em dia, diversos sistemas que permitem o uso do laudo ditado, tanto para envio para a digitação como com a transcrição direta na tela do computador por reconhecimento de voz. O grande problema está na aceitação, por parte dos radiologistas, pela implicação direta no seu modo de trabalhar e no custo de aquisição e implantação destes sistemas, sem contar que o laudo ditado requer um ambiente adequado, o mais silencioso possível, e também treinamento dos profissionais que vão utilizar a ferramenta, para reduzir $\operatorname{erros}^{(7,8)}$.

No Brasil já existem, atualmente, diversos programas, com custos os mais variados possíveis, que permitem não só que seja feito o laudo ditado, mas também o laudo com reconhecimento de voz direto na tela. Estes são mais dispendiosos e dependem de vários outros fatores, em especial do treinamento de quem lauda e do armazenamento da voz no sistema, aceitando as diversas variações nos sons emitidos.

Em excelente artigo publicado nesta edição da Radiologia Brasileira, Ferreira et al. ${ }^{(9)}$ fazem comparação entre o laudo ditado eletrônico e o sistema tradicional, 
demonstrando que o eletrônico foi mais eficiente do que o tradicional em relação ao tempo de geração dos laudos. Entretanto, referem também que, em relação ao tempo de digitação, o tradicional apresentou melhores resultados. Este artigo merece atenção especial, por documentar a diferença entre o trabalho tradicional e o uso de uma ferramenta eletrônica que cada vez mais irá fazer parte do dia-a-dia dos radiologistas brasileiros. Chama ainda a atenção para a necessidade de treinamento do pessoal e das dificuldades pessoais no uso de novas tecnologias. Estas dificuldades tenderão a se reduzir ao máximo com o uso rotineiro e treinamento contínuo do laudo digital.

A tendência é cada vez mais usarmos os métodos eletrônicos, e a figura da "digitadora", como funcionária de um serviço de Radiologia, tenderá a desaparecer com o tempo, pois com o reconhecimento de voz e laudo direto na tela o próprio radiologista já reduz os erros de digitação e de formatação do relatório elaborado. É importante, todavia, que se reduzam os custos destes sistemas, de modo a popularizar o seu uso entre nós. Já existem várias maneiras alternativas para dispormos de laudo ditado eletronicamente, como referido no artigo desta edição, que podem ser replicadas em qualquer tipo de serviço de Radiologia, otimizando o fluxo de trabalho.

Atualmente, o laudo ditado eletronicamente é perfeitamente factível e com custo relativamente baixo, e além disso permite manter a digitadora no fluxo de trabalho. Já os sistemas de reconhecimento de voz direto ainda podem ser muito melhorados, embora existam sistemas considerados excelentes e com boa performance na prática diária.

Outro fator importante a ser considerado é que o uso do PACS e do laudo ditado também tem importância no treinamento dos residentes/especializandos de Radiologia, conforme referem Gutierrez et al. ${ }^{(10)}$, mas esses autores salientam que os residentes que participaram do trabalho sinalizaram que o reconhecimento de voz é "menos confiável e mais demorado" que o sistema tradicional ditado. Esta observação deve ser vista com ressalvas, pois depende não só do sistema utilizado, mas também das condições locais e, especialmente, do treinamento dos usuários. Quanto maior a experiência e maior o tempo de utilização de qualquer sistema, os erros diminuem de maneira exponencial.

Finalmente, vale ressalvar que no Protocolo Brasileiro de Treinamento em Radiologia e Diagnóstico por Imagem $^{(11)}$ do Colégio Brasileiro de Radiologia e Diagnóstico por Imagem, a Comissão de Ensino recomenda que os residentes/especializandos adquiram os conhecimentos necessários sobre ciências básicas, incluindo os sistemas informatizados de arquivamento de imagens (PACS) e sistemas de informações hospitalares e radiológicas. Assim sendo, torna-se ainda mais importante a leitura do artigo publicado nesta edição, para servir de estímulo a todos os serviços, públicos e privados, que ofereçam treinamento para Radiologia no Brasil implantarem mais esta ferramenta tecnológica nas unidades radiológicas e aprimorar o treinamento de todos, objetivando a melhoria global da Radiologia em nosso país.

\section{REFERÊNCIAS}

1. Seltzer SE, Kelly P, Adams DF, et al. Expediting the turnaround of radiology reports in a teaching hospital setting. AJR Am J Roentgenol. 1997;168:889-93.

2. Sutton J. Speech-to-text: the next revelation for recording data. Radiol Manage. 1997;19:50-3

3. Wheeler S, Cassimus GC. Selecting and implementing a voice recognition system. Radiol Manage. 1999;21:37-42.

4. Mehta A, Dreyer K, Boland G. et al. Do picture archiving and communication systems improve report turnaround times? J Digit Imaging. 2000;13(2 Suppl 1):105-7.

5. Freeh M, Dewey M, Brigham L. Evaluating a voice recognition system: finding the right product for your department. J Digit Imaging. 2001;14(2 Suppl 1):6-8.

6. Langer S. Radiology speech recognition: workflow, integration, and productivity issues. Curr Probl Diagn Radiol. 2002;31:95-104.

7. Rana DS, Hurst G, Shepstone L, et al. Voice recognition for radiology reporting: is it good enough? Clin Radiol. 2005;60:1205-12.

8. McGurk S, Brauer K, Macfarlane TV, et al. The effect of voice recog nition software on comparative error rates in radiology reports. $\mathrm{Br} \mathrm{J}$ Radiol. 2008;81:767-70.

9. Ferreira DM, Cohrs FM, Lederman HM, et al. Comparação dos tem pos de geração e digitação de laudos radiológicos entre um sistema eletrônico baseado em voz sobre IP (VoIP) e um sistema tradicional baseado em papel. Radiol Bras. 2010;43:7-12.

10. Gutierrez AJ, Mullins ME, Novelline RA. Impact of PACS and voicerecognition reporting on the education of radiology residents. J Digit Imaging. 2005;18:100-8.

11. Colégio Brasileiro de Radiologia e Diagnóstico por Imagem. Protocolo Brasileiro de Treinamento em Radiologia e Diagnóstico por Imagem. [acessado em 23 de janeiro de 2010]. Disponível em: http://www.cbr. org.br/pdf/r_c/rddi/protocolo09.pdf 